\title{
THE MYOCARDIAL FACTOR IN MITRAL VALVE DISEASE
}

\author{
BY \\ H. A. FLEMING* AND PAUL WOOD \\ From the Cardiac Department, Brompton Hospital, and the Institute of Cardiology
Received June 22, 1958
}

Before the beneficial results of mitral valvotomy were established, it was customary to follow MacKenzie's teaching and invoke myocardial weakness as the major factor in causing the heart to fail in its functions in the presence of mitral valve disease (Lewis, 1946). Baker et al. (1950), while allowing the possibility, emphasized the prime importance of the mechanical fault in the vast majority of cases. Subsequent experience of the progress of cases treated on this basis with great symptomatic and hæmodynamic improvement confirms the truth of this assertion. Many workers have published large series of such cases, Baker et al. (1952) and Wood (1954) making important reports from this country.

However, a small percentage of cases continues to appear in which mechanical obstruction does not seem to be of sufficient degree to explain the symptoms, and these have been attributed to myocardial dysfunction (Wade et al., 1952; Harvey et al., 1955; Ferrer et al., 1955; and Soloff et al., 1957). The physiological criteria on which such a diagnosis is based are explicit enough, but no well-defined clinical picture has emerged. The frequency of such cases is also uncertain. Harvey (1955) describes 8 examples among 60 cases of mitral valve disease studied, but in our experience the condition is not as common as this.

The object of this communication is to draw a more faithful portrait of the syndrome in question, to offer a suggestion concerning its nature, and to encourage more rational and effective treatment.

\section{MATERIAL}

The present study is based on a review of 750 cases of mitral stenosis under the care of one of us (P.W.) at the Brompton Hospital and the National Heart Hospital during the past eight years. Only 24 cases with unquestionable myocardial dysfunction associated with unimportant valve disease could be found, an incidence of 3.2 per cent. In the majority the question of a myocardial factor being responsible for the symptoms was raised on completion of the history and physical examination: cardiac catheterization was carried out to test the truth of this conclusion. In a minority the myocardial factor was first invoked when physiological studies demonstrated the association of mild stenosis with a low cardiac output.

Characteristically the cases had intermittent but incapacitating symptoms over a long period of time and most of them had had objective evidence of heart failure without a raised pulmonary artery pressure. The symptoms included dyspnœa on effort, nocturnal dyspnœa, orthopnœa, fatigue, and ankle œdema. Systemic embolism was frequent, and syncope occurred in three cases. Radiographs at times showed interstitial pulmonary œdema and interlobular septal lines. In these cases the auscultatory signs were those of pure stenosis of less than critical severity-a relatively quiet first heart sound, a late opening snap, and a short mitral diastolic murmur (Wood, 1956; and Wells, 1957). Occasionally a third heart sound was noted at the apex. A mitral pansystolic murmur was heard in 9 cases $(37 \%)$ but it was never loud and never accompanied by other clinical features suggesting serious mitral regurgitation.

In an attempt to isolate a homogeneous group from which a distinct clinical syndrome might crystallize, all cases with possible complicating factors were excluded. Thus cases were rejected on

* Present address :-Hallstrom Institute of Cardiology, Royal Prince Alfred Hospital, Sydney, N.S.W. 
the following grounds-raised pulmonary vascular resistance (more than 6 units), pulmonary thrombo-embolic disease, cor pulmonale, coronary ischæmia, systemic hypertension, previous bacterial endocarditis, and rheumatic disease of valves other than the mitral. No cases were anæmic and none had evidence of rheumatic activity.

The relevant data from the 24 cases are summarized below.

\section{Clinical Findings}

Sex. 21 women $(87.5 \%) ; 3$ men $(12.5 \%)$

Age. 21-55 years; average, 43 years

Length of history. 2-20 years; average, 9 years

Rheumatic history. $19(80 \%)$; Recurrent rheumatic history: $5(26 \%)$

Left heart failure. $20(83 \%)$; Congestive failure: $17(71 \%)$

Systemic embolism. $11(46 \%)$

Cerebral embolism. 10 (91\% of embolic cases)

Repeated embolism. $6(55 \%$ of embolic cases $)$

Syncope. $3(12.5 \%)$; Angina $2(8 \%)$

Atrial fibrillation. $24(100 \%)$

Electrocardiogram with normal QRS complexes. $22(90 \%)$

Cardiothoracic ratio. $0.42-0 \cdot 75$; average, 0.52

\section{Physiological Findings}

Cardiac output. 1.7-4.7 1./min; average, $3 \cdot 21 . / \mathrm{min}$.

Mitral index. $17-100$ per cent; average 50 per cent

Indirect left atrial pressure (measured from the sternal angle). $0-17 \mathrm{~mm} . \mathrm{Hg}$; average, 7 $\mathrm{mm} . \mathrm{Hg}$

Pulmonary vascular resistance. $0 \cdot 5-6$ units; average, $2 \cdot 3$ units.

\section{ANALYSIS OF CASES}

The 150 surgical cases of mitral stenosis reported by Wood (1954) are included in the present series of 750 cases from which the 24 with myocardial dysfunction have been isolated, and the detailed analysis of those 150 will be used for comparison with the cases in this report. The surgical group is chosen because it consisted of cases of pure or dominant critical mitral stenosis that were submitted to operation, and it is from this group in particular that distinction must be made. This is especially important because operation in those cases without mitral obstruction must be avoided.

The average age of 43 years is rather more than in the control group (37 years), and the F:M sex ratio of 7:1 higher than the 4:1 ratio in uncomplicated mitral stenosis. In the "myocardial insufficiency" cases of Harvey et al. (1955) the average age was 38 years compared with 36 years in their stenotic group; the F:M sex ratio was 3:5 in the former and $1: 1$ in the latter.

A rheumatic history was obtained in 80 per cent. of the present series; this is higher than in the controls $(60 \%)$ but may not be statistically significant. Recurrent attacks of rheumatism occurred less frequently $(26 \%)$ than in the controls $(31 \%)$. These figures give little support to the view that the increased myocardial damage is related to the severity or frequency of previous rheumatic activity.

The duration of symptoms ( 9 years) was longer than in those with serious stenosis ( $7 \cdot 3$ years, from onset to total incapacity). In the present series no patient was totally incapacitated after treatment. The history tended to be remittent with spells of failure interspersed with spells of near normal performance. The response to medical treatment was usually good, but this had to be maintained to prevent a relapse. Harvey (1955) made similar observations. In the present series one patient only has died-a 36-year-old woman with a ten-year history of symptoms who died in congestive heart failure. No details of her treatment are available. At necropsy the valve was pliable, not incompetent, and the orifice measured $0.5 \times 2.0 \mathrm{~cm}$.; there was a giant left atrium but the left ventricle was only moderately dilated and measured $1.1 \mathrm{~cm}$. in thickness: histological examination of the myocardium was not carried out. 
Systemic embolism occurred in 46 per cent of these cases, but in only 13-14 per cent of stenotic controls (Wood, 1954; and Belcher and Somerville, 1955). In 91 per cent of them the cerebral vessels were involved, a higher figure than the 75 per cent of Wood and the 59 per cent of Belcher and Somerville. In 55 per cent of our cases two or more systemic emboli had occurred by the time they were seen, contrasting with the 35 per cent of recurrent emboli found by Belcher and Somerville. These figures leave no doubt about the greater risk of embolism in the group with myocardial dysfunction and mild stenosis. That this is not related to obstruction of the mitral orifice is self evident, but may be emphasized by the history of a patient in the series. A woman, aged 41 years, who had previously had a right brachial embolus, persuaded her doctors to allow the mitral valve to be explored, because of the severity of her symptoms. At operation the valve orfice was found to be of almost normal size and the commissures were cut not more than $3 \mathrm{~mm}$. to the valve ring. Following operation she was no better, and some months later suffered a left hemiplegia. This, of course, is in keeping with the well recognized fact that emboli may occur with trivial mitral stenosis. Wood (1954) reported this and it has since been fully confirmed. McDonald et al. (1957) reported no systemic emboli in patients with the largest valve orifices, but they studied only 44 cases. Harvey et al. (1955) make no mention of systemic emboli in their group of patients with myocardial insufficiency.

The increased tendency to embolism may be related to the high incidence of atrial fibrillation which occurred in all our cases, as opposed to 41 per cent in Wood's surgical cases and 66 per cent in his cases with a history of systemic embolism. Belcher and Somerville record that 78 per cent of their embolic cases were fibrillating. It is generally agreed that atrial fibrillation increases the tendency to embolism. In the present series the low cardiac output with the sluggish flow through the heart would also be expected to increase the chance of clot forming in the atrium. The high incidence of atrial fibrillation may be related to the relatively advanced age of many of these patients.

The left atrium was unduly enlarged in only two cases, but otherwise was as usual for mild mitral stenosis with atrial fibrillation. Wood (1954) has reported that in mitral stenosis with atrial fibrillation the size of both atria is larger than with sinus rhythm, which suggests that the atrial enlargement follows rather than causes the fibrillation.

Symptoms of left heart failure had been present in 83 per cent of our cases and of congestive failure with œdema in 72 per cent. Three patients complained of syncope and at catheterization their cardiac outputs measured only $2 \cdot 0,2 \cdot 2$, and 4.0 litres $/ \mathrm{min}$., and this could well have been the basis for the symptom. Two patients had angina pectoris.

There was nothing specific about the electrocardiogram, which showed normal QRS complexes in all but two cases; one of the exceptions had slight left, and the other slight right, ventricular hypertrophy. The $\mathrm{T}$ waves were normal except for digitalis $\mathrm{S}-\mathrm{T}$ depression.

Radiological evidence of cardiac enlargement was never more than moderate, the left atrium and the right heart usually being involved. In eight cases, the left ventricle also appeared to be enlarged, but never more than slightly. The normal appearance of the left ventricle at operation in one case belied clinical and radiological evidence of considerable enlargement. In another, with a giant left atrium, necropsy meted out similar discipline. The cardiothoracic ratio in the series averaged 0.52. Thus cardiac enlargement did not distinguish these cases from those with mitral obstruction. This is in contrast to the views of Ellis et al. (1957) who described an unusually large heart that was not explained by the valvular disease. On the other hand Harvey et al. (1955) found that the average heart size in the myocardial insufficiency group was similar to that in the stenotic group, although the largest individual hearts were found in those with myocardial insufficiency.

Mitral valve calcification of minor degree was present in 15 per cent and the left atrium was calcified in one case. The left atrial appendix was never conspicuously enlarged.

\section{Physiological Studies}

Right heart catheterization was carried out in 22 of the 24 patients. The most impressive physiological feature was the low cardiac output, which ranged between 1.7 and $4 \cdot 7$, and averaged $3 \cdot 2$ litres/min. In Wood's (1954) group without much rise of the pulmonary vascular resistance the out- 
put was 4.0 to 4.6 litres $/ \mathrm{min}$., but it was only 3.6 litres $/ \mathrm{min}$. in those with atrial fibrillation. Harvey et al. (1955) stated that the resting outputs were similar in the mitral stenotic and the myocardial insufficiency groups and did not think this was a differentiating factor; but they emphasize failure of the cardiac output to rise properly on exercise in those with myocardial insufficiency-a point of considerable diagnostic value. In our cases measurements of cardiac output were made at rest only.

The indirect left atrial pressure at rest measured from 0 to $17 \mathrm{~mm}$. $\mathrm{Hg}$ (average $7 \mathrm{~mm}$.), with reference to the sternal angle, and the mitral index (Wood, 1954) from 17 to 100 with an average of 50 per cent, indicating an estimated variation from average stenosis to no mitral obstruction at all. In one case with an index of 17 per cent the valve at autopsy was found to measure $0.5 \times 2.0 \mathrm{~cm}$., and in another with an index of 26 per cent the valve opening at operation was said to be of nearly normal dimensions. It should be pointed out, however, that the index breaks down when the rise in left atrial pressure is due to left ventricular dysfunction or to mitral regurgitation, and that only the Ry/v ratio (Owen and Wood, 1955) or a directly measured diastolic pressure gradient across the mitral valve provides valid evidence of the degree of stenosis. In 7 cases the indirect left atrial pressure change on exercise was studied and the rise was moderate (range 0 to $24 \mathrm{~mm}$., average $10 \mathrm{~mm}$.).

The pulmonary vascular resistance ranged from 0.5 to 6.0 units (average 2.3 units), i.e. from normal to moderate elevation.

\section{Discussion}

Although a left ventricular myopathy is commonly supposed to explain the syndrome, it is remarkable what little evidence of disease is shown by the left ventricle clinically, electrocardiographically, radiologically, at operation, and at autopsy. The average left atrial pressure of only 7 $\mathrm{mm}$. $\mathrm{Hg}$ with reference to the sternal angle denies any serious elevation of the left ventricular enddiastolic pressure at rest, but direct observations during exercise might be of value.

The one constant feature of all our cases was atrial fibrillation, usually of many years' duration. Exceptions included a man, aged 21 years, with large atria which fibrillated for the first time at catheterization, and another with paroxysmal fibrillation over a long period of time.

It is suggested, therefore, that atrial fibrillation is the essence of the syndrome under discussion, accounting for the symptoms, the low cardiac output, and the high incidence of systemic embolism. There is good experimental evidence in animals (Jones and Sclapp, 1945; and Wegria et al., 1950) that the onset of atrial fibrillation is associated with a sharp fall in cardiac output which returns to normal when sinus rhythm is restored. Hansen et al. (1952) and Broch and Müllar (1957), studying digitalized patients with atrial fibrillation, showed that restoration of sinus rhythm increased the resting cardiac output and improved the response to exercise.

In one of our cases uncontrolled atrial fibrillation at the time of admission was associated with a bundle-branch block pattern (Fig. 1) which returned to normal when the rate was controlled with digitalis. This happening, which is not very rare, suggests that the nutrition of the myocardium may suffer from uncontrolled atrial fibrillation. Wegria et al. (1950) demonstrated a diminished coronary blood flow during atrial fibrillation. It must be conceded, therefore, that in the cases under discussion periods of rapid fibrillation may have permanently damaged the myocardium. At the present time it is impossible to say whether the symptoms are due to the rhythm change itself or to a nutritional myocardiopathy caused by the rhythm change. Atrial fibrillation is, however, very uncommon in myocardiopathies of other kinds, and there is no reason to believe that it would be caused by rheumatic myocarditis. Negative left appendicular biopsies support this view.

One reason for inculpating the rhythm change itself, rather than a secondary nutritional myocardiopathy, is the constancy of a normal QRS-T electrocardiographic pattern. In myocardiopathies of other kinds the $T$ wave is nearly always inverted in left ventricular surface leads or their equivalents (Brigden, 1957), as it is when heart failure complicates prolonged paroxysmal tachycardia in a previously normal heart.

It is surprising that the heart was not larger in cases with a long history of failure and atrial fibrillation, but the manner in which the cases were selected may account for this. Thus several with 


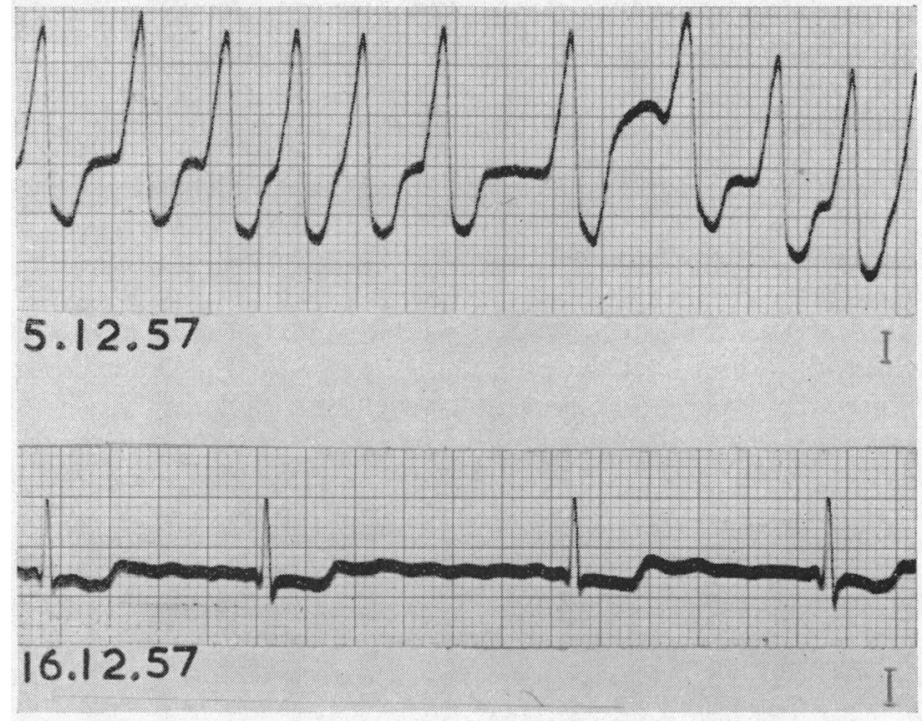

FiG. 1.-Electrocardiogram (lead I) of a case in the present series, showing the abnormal ventricular complexes before the rate was controlled with digitalis.

larger hearts were rejected because there was significant mitral regurgitation, but of course this could well have been functional. We have frequently observed a transient increase in heart size during a paroxysm of fibrillation. Evans and Swan (1954) found no cardiac enlargement in lone fibrillation, but their cases were essentially benign and associated with a slow rate and absence of symptoms, including systemic embolism. Wood (1954) found both atria larger in atrial fibrillation than in sinus rhythm. However, when we compared the cardiothoracic ratio in 15 cases of critical mitral stenosis in sinus rhythm with no more than moderate elevation of the pulmonary vascular resistance with a matched series of 15 cases in atrial fibrillation there was no significant difference (sinus rhythm $0.46-0.66$, average 0.57 ; A.F. $0 \cdot 47-0 \cdot 85$, average 0.60 ), although the largest hearts were fibrillating. McDonald et al. (1957) also found that varying degrees of cardiac enlargement were found equally in patients with widely differing types of mitral valve disease and were of no help in differentiating them.

From this study there emerges a picture of a middle-aged woman presenting with a long history of intermittent dyspnœa and œdema. She has probably had a systemic embolism, very likely cerebral, and complains bitterly of fatigue. The signs are those of mild mitral stenosis with evidence of left heart failure or congestive failure, and without signs of a raised pulmonary vascular resistance. Certainly she has atrial fibrillation. The electrocardiogram and chest radiograph are indistinctive. Cardiac catheterization reveals a low cardiac output responding poorly to exercise, a near normal right heart pressure, and a left atrial pressure that is within normal limits at rest but rises moderately on exercise. Two of our cases were submitted to operation, but in neither was the stenosis tight enough to warrant valvotomy. No psychological benefit followed the operation and one of the patients continued to have emboli.

The frequent occurrence of embolism led us to treat these patients with anticoagulants permanently. So far the results have been encouraging and are expected to prove superior to left atrial appendicectomy. Effective control of heart rate by means of digitalis is essential and rewarding.

Although the cases reported by Harvey et al. (1955) would appear to be similar to ours in many respects, our incidence is much lower: this difference may be due to our rigid method of selection. More advanced cases than ours may exist in considerable numbers, but they present with serious 
mitral regurgitation or with multiple valve lesions, and it is very difficult to know whether the rhythm change or the valve disease is chiefly responsible for the symptoms.

\section{SUMMARY}

Myocardial dysfunction, rather than the mechanical effects of valve lesions, was responsible for ill-health in 3.2 per cent of 750 cases of rheumatic mitral valve disease. The recognition of these cases is important, because operation is not indicated.

The clinical picture was characterized by a long history of fatigue, recurrent heart failure, systemic embolism, and atrial fibrillation, associated with signs of mild mitral stenosis.

The chief physiological findings were a low cardiac output, almost normal left atrial pressure at rest, and normal or only slightly raised pulmonary vascular resistance.

Clinical, electrocardiographic, radiological, physiological, operative, and necropsy data failed to reveal convincing evidence of primary myocardial fault, and the syndrome appears to be an unusual consequence of atrial fibrillation in the presence of mild mitral valve disease.

When normal rhythm cannot be restored or maintained, relatively good health may be enjoyed with the aid of adequate doses of digitalis and permanent anticoagulant therapy. Mitral valvotomy does not improve cardiac function nor prevent embolism.

\section{REFERENCES}

Baker, C., Brock, R. C., and Campbell, M. (1950). Brit. med. J., 1, 1283.

,,--- , and Wood, P. (1952). Brit. med. J., 1, 1043.

Belcher, J. R., and Somerville, W. (1955). Brit. med. J., 2, 1000.

Brigden, W. (1957). Lancet, 2, 1179.

Broch, O. J., and Muller, O. (1957). Brit Heart J., 19, 222.

Ellis, L. B., Abelman, W. H., and Harken, D. E. (1957). Circulation, 15, 924.

Evans, W., and Swan P. (1954) Brit. Heart J., 16, 189.

Ferrer, M. I., Harvey, R. M., Wylie, R. H., Himmelstein, A., Lambert, A., Kuschner, M., Cournand, A., and Richards, D. W. (1955). Circulation, 12, 7.

Hansen, W. R., McClendon, R. L., and Kinsman, J. M. (1952) . Amer. Heart J., 44, 499.

Harvey, R. M. (1955). Cardiovascular Surgery (Henry Ford Symposium). W. B. Saunders, Philadelphia.

- , Ferrer, M. I., Samet, P., Bader, R. A., Bader, M. E., Cournand, A., and Richards, D. W. (1955) Circulation, 11, 531.

Jones, A. M., and Sclapp, W. (1945). Brit. Heart J., 7, 211

Lewis, Sir T. (1946) Diseases of the Heart. MacMillan, London.

McDonald, L., Dealy, J. B., Rabinowitz, M., and Dexter, L. (1957). Medicine, Baltimore, 36, 237.

Owen, S. G., and Wood, P. (1955). Brit Heart J., 17, 41.

Soloff, L. A., Zatuchni, J., and Mark, G. E. (1957). Amer J. med. Sci., 233, 518.

Wade, G., Werkö, L., Eliasch, H., Gidland, A., and Largerlöf, H. (1952). Quart. J. Med., $21,361$.

Wegria, R., Frank, C. W., Misrahy, G. A., Sioussat, R. S., Sommer, L. S., and McCormack, G. H. (1950). Amer. J. Physiol., 163, 136.

Wells, B. G. (1957). Brit. med. J., 1, 551.

Wood, P. (1954). Brit. med. J., 1, 1051

(1956). Diseases of the Heart and Circulation. 2nd ed., Eyre and Spottiswoode, London. 